\title{
Is Persistent Thick Copious Mucus a Long-Term Symptom of COVID-19?
}

\author{
Patrick Manckoundia $^{1,2}$, Evelyne Franon ${ }^{3}$ \\ ${ }^{1}$ Department of Geriatrics and Internal Medicine, Dijon University Hospital, Dijon, France \\ 2UMR Inserm/U1093 Cognition, Action, Sensorimotor Plasticity, University of Burgundy and Franche Comté, Dijon, France \\ ${ }_{3}^{3}$ Medical Office, 9, rue Jean Sans Peur, Dijon, France
}

Received: 12/11/2020

Accepted: 29/11/2020

Published: $29 / 12 / 2020$

How to cite this article: Manckoundia P, Franon E. Is persistent thick copious mucus a long-term symptom of COVID-19? EJCRIM 2020;7:

doi:10.12890/2020_002145.

Conflicts of Interests: All of the authors declare that they have no known competing financial interests or personal or other relationships with other people or organizations within 3 years of beginning the work submitted that could inappropriately influence (bias) their work.

Ackowledgements: We would like to thank Mrs Suzanne Rankin (Dijon University Hospital) for the manuscript language revision.

This article is licensed under a Commons Attribution Non-Commercial 4.0 License

\section{ABSTRACT}

Introduction: The typical clinical picture of COVID-19 is gradually becoming clearer, both in the acute phase and in the long-term. However, new symptoms are gradually being identified. We describe a long-term symptom that has not yet been reported.

Case description: A 49-year-old man consulted for persistent asthenia. The general practitioner found a fever (39.2 $\left.{ }^{\circ} \mathrm{C}\right)$, and COVID-19 was confirmed by the polymerase chain reaction test. Further symptoms appeared, notably thick, white, painless tracheal hypersecretion for 3 months before diminishing, without disappearing.

Conclusion: Non-inflammatory tracheal hypersecretion, not yet reported in COVID-19, may be an additional long-term symptom. The hyperstimulation of tracheal goblet cells secreting mucus is 1 pathophysiological hypothesis.

\section{LEARNING POINTS}

- Painless, non-inflammatory tracheal hypersecretion, which has yet to be described in post-acute COVID-19, may be an additional longterm symptom of the disease.

- The hyperstimulation of mucus-secreting tracheal goblet cells by the coronavirus, leading to tracheal discomfort and a feeling of suffocation, is 1 pathophysiological hypothesis.

\section{KEYWORDS}

COVID-19, tracheal hypersecretion, long-term symptom

\section{INTRODUCTION}

Since the end of 2019, the world has been grappling with the coronavirus disease (COVID-19) pandemic. The typical clinical picture for COVID-19 is now well known. The most common symptoms in the acute phase are fever, fatigue and cough ${ }^{[1]}$. However, new symptoms which were initially described as atypical are gradually being identified, and the number of long-term symptoms identified has also increased. We report the case of a patient with a symptom not yet described in the literature but which could be a long-term symptom of COVID-19. 


\section{CASE DESCRIPTION}

A 49-year-old man consulted his general practitioner (GP) for significant and unusual asthenia. He had no particular medical history, including no heart or vascular disease, respiratory condition, diabetes, kidney failure, immune deficiency or obesity. He did not smoke or drink alcohol and he did not take any regular treatment.

The first symptom, asthenia, occurred at the weekend and the patient had initially attributed it to an exhausting work week. When he continued to feel very tired despite the weekend rest, he consulted his GP, who found a fever of $39.2^{\circ} \mathrm{C}$. The patient was given 2 days of sick leave and prescribed paracetamol for his symptoms, and he was sent for COVID-19 screening by the polymerase chain reaction test. The test yielded a positive result. In the meantime, other symptoms had appeared including a dry cough, dysgeusia and headache. The patient's health status was not considered to be of concern and he was not hospitalized. His sick leave was extended by 14 days and the paracetamol continued, in addition to rest and regular follow-up with his GP. The course of the disease was progressively positive. After 5 days the fever, dry cough, dysgeusia and headache vanished, and the asthenia significantly decreased. However, tracheal hypersecretion appeared in the form of thick, white mucus. The patient did not have a sore throat, indicating that the secretions were not the result of an inflammatory phenomenon. The hypersecretion was exacerbated in the decubitus position, forcing the patient to get up and spit frequently to relieve the sensation of tracheal obstruction. During follow-up he specified that the phenomenon was not bronchopulmonary but a painless tracheal hyperproduction of mucus, and he denied consuming any unusual food or drink. Inspection of the mouth and throat found no inflammatory lesions or any other atypical features. The tracheal hypersecretion persisted for 3 months and then progressively decreased, but it did not resolve completely. The otorhinolaryngology examination remained normal. The patient has given his consent for this publication.

\section{DISCUSSION}

This observation is novel. To our knowledge, no case of long-term painless non-inflammatory tracheal hypersecretion has been attributed to COVID-19 in the literature.

The acute clinical picture of COVID-19, which can be compared to a severe influenza syndrome, classically involves a nearly constant fever, cough in more than $2 / 3$ of cases, dyspnoea in more than half of patients, asthenia in 38 to $44 \%$ of cases, myalgia in $44 \%$ of patients and production of sputum in $1 / 3$ of cases ${ }^{[1,2]}$. Symptoms such as headache, sore throat or nasal obstruction are less common ${ }^{[1,3]}$. Other symptoms were initially described as atypical. These include digestive signs such as diarrhoea in a quarter of cases, and anorexia and nausea in $18 \%$ of patients ${ }^{[4]}$. Anosmia and ageusia have also been reported in cases of COVID-19 and can be early signs of the disease ${ }^{[3]}$. Finally, recent medical findings also describe the possibility of skin damage, related to peripheral vascular disorder, in patients with COVID-19. The more serious forms cause pneumonia up to acute respiratory distress ${ }^{[5]}$, requiring hospitalization in intensive care. Ocular manifestations such as viral conjunctivitis have also been described in severe forms ${ }^{[6]}$.

The most commonly reported long-term symptoms include fatigue, shortness of breath, cough, joint pain and chest pain. Other reported long-term symptoms are difficulty with cognition and concentration, depressive signs, muscle pain, headache and intermittent fever or heart palpitations ${ }^{[7]}$. Although reported in some acute forms of COVID-19, tracheal hypersecretion has never been described as a longterm symptom of the disease. The accumulation of mucus in the respiratory tract has been reported in severe forms of COVID-19 with pneumonia and may be associated with COVID-19-related acute respiratory distress syndrome ${ }^{[8]}$. However, in the present case, the patient did not have severe COVID-19 infection and had no signs of pneumonia. In a series of 38 patients with COVID-19, autopsy often found dense mucoid material within the lumina of the bronchi and bronchiolar branches ${ }^{[9]}$. Other autopsy studies have reported the presence of copious mucinous secretions in the lower respiratory tract of patients with COVID-19 ${ }^{[10]}$. Apart from such changes in the distal respiratory tract, severe mucoid tracheitis or tracheobronchitis has been found in 1/3 of the postmortem examinations on patients with COVID-19 [11]. Furthermore, as shown in our case report, painless and non-inflammatory tracheal hypersecretion may be an additional residual clinical manifestation of COVID-19. One pathophysiological hypothesis is that tracheal goblet cells are hyperstimulated by the coronavirus, which causes the mucus to thicken and accumulate, leading to tracheal discomfort and a feeling of suffocation. In addition, a parallel can be drawn with the hypersecretion of mucus in the airway observed in respiratory syncytial virus infection, where a role for interleukin-17 has been suggested ${ }^{[12]}$. One hypothetical pathophysiological explanation for the thick and sticky mucus that is produced in the airways in acute severe forms of COVID-19 is the dysregulation of neutrophil extracellular traps and neutrophil elastase that occurs during the hyperinflammatory immune response ${ }^{[8]}$. The pathophysiology of this novel phenomenon should be investigated further.

\section{CONCLUSION}

Many advances have been made in the description and understanding of COVID-19, but it is likely that this disease has not yet delivered all its truths. Tracheal hypersecretion could thus potentially be a long-term symptom of COVID-19. 


\section{REFERENCES}

1. Guan WJ, Ni ZY, Hu Y, Liang WH, Ou CQ, He JX, et al. Clinical characteristics of coronavirus disease 2019 in China. N Engl J Med 2020;382:1708-1720.

2. Huang C, Wang Y, Li X, Ren L, Zhao J, Hu Y, et al. Clinical features of patients infected with 2019 novel coronavirus in Wuhan, China. Lancet 2020;395:497-506.

3. Lechien JR, Chiesa-Estomba CM, De Siati DR, Horoi M, Le Bon SD, Rodriguez A, et al. Olfactory and gustatory dysfunctions as a clinical presentation of mild-to-moderate forms of the coronavirus disease (COVID-19): a multicenter European study. Eur Arch Otorhinolaryngol 2020;277:2251-2261.

4. Lin L, Jiang X, Zhang Z, Huang S, Zhang Z, Fang Z, et al. Gastrointestinal symptoms of 95 cases with SARS-CoV-2 infection. Gut 2020;69:997-1001.

5. Gabutti G, d'Anchera E, Sandri F, Savio M, Stefanati A. Coronavirus: update related to the current outbreak of COVID-19. Infect Dis Ther 2020;8:1-13.

6. Chen L, Liu M, Zhang Z, Qiao K, Huang T, Chen M, et al. Ocular manifestations of a hospitalised patient with confirmed 2019 novel coronavirus disease. Br J Ophthalmol 2020;104:748-751.

7. Centers for Disease Control and Prevention [Internet]. Long-term effects of COVID-19. Available from: https://www.cdc.gov/coronavirus/2019-ncov/long-term-effects.html (accessed 19 November 2020).

8. Farooqi FI, Morgan RC, Dhawan N, Dinh J, Yatzkan G, Michel G. Airway hygiene in COVID-19 pneumonia: treatment responses of 3 critically ill cruise ship employees. Am J Case Rep 2020;21:e926596.

9. Carsana L, Sonzogni A, Nasr A, Rossi RS, Pellegrinelli A, Zerbi P, et al. Pulmonary post-mortem findings in a series of COVID-19 cases from northern Italy: a two-centre descriptive study. Lancet Infect Dis 2020;20:1135-1140.

10. Wang C, Xie J, Zhao L, Fei X, Zhang H, Tan Y, et al. Alveolar macrophage dysfunction and cytokine storm in the pathogenesis of two severe COVID-19 patients. EBioMedicine 2020;57:102833.

11. Menter T, Haslbauer JD, Nienhold R, Savic S, Hopfer H, Deigendesch N, et al. Postmortem examination of COVID-19 patients reveals diffuse alveolar damage with severe capillary congestion and variegated findings in lungs and other organs suggesting vascular dysfunction. Histopathology 2020;77:198-209.

12. Mukherjee S, Lindell DM, Berlin AA, Morris SB, Shanley TP, Hershenson MB, et al. IL-17-induced pulmonary pathogenesis during respiratory viral infection and exacerbation of allergic disease. Am J Pathol 2011;179:248-258. 